\title{
O vestir na vida dos idosos: contribuições da ergonomia e das tecnologias assistivas
}

Dressing in elderly's daily lives: contributions from ergonomics and assistive technologies

\section{Crislaine Gruber} Mestre em Design (UDESC) crislaine.gruber@ifsc.edu.br

\section{Eugenio Andrés Díaz Merino}

Doutor em Engenharia de Produção (UFSC) eugenio.merino@ufsc.br

\section{Giselle Schmidt Alves Díaz Merino}

Doutora em Engenharia de Produção (UFSC) gisellemerino@gmail.com 


\title{
Lizandra Garcia Lupi Vergara
}

Doutora em Engenharia de Produção (UFSC)

I.vergara@ufsc.br

\author{
O vestir na vida dos idosos: contribuições da ergonomia e das \\ tecnologias assistivas \\ Dressing in elderly's daily lives: contributions from ergonomics and assistive \\ Technologies
}

\author{
Crislaine Gruber, Eugenio Andrés Díaz Merino, Giselle Schmidt Alves Díaz \\ Merino e Lizandra Garcia Lupi Vergara
}

\section{Resumo}

A ergonomia tem como prerrogativa adaptar produtos, serviços e estratégias às pessoas, considerando suas habilidades e limitações. As Tecnologias Assistivas (TAs) são dispositivos, serviços, estratégias ou práticas que minimizam problemas decorrentes de limitações funcionais dos indivíduos. Nesse sentido, podem auxiliar os idosos nas Atividades de Vida Diária (AVDs), tais como vestir. Considerando o envelhecimento populacional uma realidade mundial, este trabalho apresenta um levantamento sobre a interação de idosos com uma TA para vestir a fim de verificar sua percepção acerca do uso. $\mathrm{O}$ teste foi realizado por cinco idosos e consistiu em responder a um questionário sobre demandas, necessidades e problemas com o vestuário, vestir um par de meias utilizando o dispositivo de TA e, por fim, preencher o questionário de avaliação do uso do dispositivo. Observou-se que uma das principais dificuldades no uso do produto é a utilização do folheto de instruções. Além disso, nenhum dos participantes conseguiu vestir completamente o par de meias. Concluídos os testes, foi feita a avaliação dos instrumentos utilizados e destacadas as opiniões dos participantes em relação às vantagens e desvantagens do produto.

Palavras- chave: Usuário idoso. Atividades da Vida Diária (AVDs). Ergonomia

\begin{abstract}
Ergonomics aims to adapt products, services and strategies to make them compatible with the needs, abilities and limitations of people. Assistive technologies (AT) are devices, services, strategies and practices that reduce problems caused by functional limitations of individuals. They can help elderly to accomplish activities of daily living like dressing. Considering the aging of world population, this paper presents a research on interaction between the elderly and an assistive dressing aid to verify their perceptions about the use of the AT device. Five participants used the AT device to put a pair of socks, and evaluated this experience. We found that the main difficulty for elderly in using the device was understanding the manual. Participants could not dress the pair of socks completely. Completing the tests, we evaluated the instruments and highlighted the participant's opinions regarding advantages and disadvantages of the product.
\end{abstract}

Keywords: Elderly. Activities of daily living (ADLs). Ergonomics. 


\section{Introdução}

Se para muitos a dificuldade para vestir-se reside em escolher qual roupa usar, para tantos outros a essa é somado o seguinte desafio: como vestir, despir, fechar e abrir as roupas. Botões, zíperes, ganchos, reguladores e elásticos são exemplos de aviamentos utilizados para viabilizar o vestir. Em muitos casos, seria impossível vestir se não houvesse um fecho ou um botão. Porém a complexidade dessa atividade aumenta quando é inserido na peça um sistema de fechamento e abertura que exige movimentos motores finos, por exemplo.

Ao desenvolver um projeto de vestuário, deve-se considerar o ato de vestir. Tendências de moda, pesquisas de comportamento, novos materiais e cores são informações utilizadas e importantes para o consumidor, mas é preciso pensar no usuário e nas diferentes restrições que ele pode apresentar. Indivíduos que apresentam limitações funcionais relacionadas aos diversos aspectos da vida, como os idosos, podem ser beneficiados por Tecnologias Assistivas (TAs), dispositivos, serviços, estratégias ou práticas que minimizam os problemas decorrentes dessas incapacidades (COOK; POLGAR; HUSSEY, 2008).

Plos et al. (2012) afirmam que tanto o design de TAs quanto a gestão de uma deficiência estão relacionadas ao trabalho do ergonomista. A ergonomia, devido ao seu caráter interdisciplinar, é uma ferramenta de grande importância em estudos e projetos destinados a idosos, contribuindo para a segurança, conforto e desenvolvimento das atividades rotineiras da vida diária com baixo gasto de energia física, e aumentando sua autonomia e autoestima (PAIVA; SANTOS, 2012).

Considerando o envelhecimento populacional uma realidade mundial, este trabalho apresenta um levantamento sobre a interação de usuários idosos com uma TA para vestir a fim de verificar a percepção dos participantes acerca do uso do dispositivo testado.

\section{Fundamentação teórica}

\subsection{Ergonomia}


A Associação Internacional de Ergonomia (IEA) define a ergonomia como a disciplina científica que trata da compreensão das interações entre os seres humanos e outros elementos de um sistema, e a profissão que aplica teorias, princípios, dados e métodos, a projetos que visam otimizar o bem-estar humano e a performance global dos sistemas (ABERGO, 2001).

Iida (2005) destaca que, inicialmente, as aplicações da ergonomia restringiram-se à indústria e ao setor militar e aeroespacial; hoje, contudo, elas expandem-se para a agricultura, o setor de serviços e a vida diária das pessoas. Segundo Paschoarelli (2013, p.77), a ergonomia visa a contribuir para que os atritos nas relações entre tecnologia e usuário sejam minimizados, "não apenas no que tange às atividades ocupacionais, mas também a toda complexidade que envolve as atividades da vida diária."

Portanto, a ergonomia pode contribuir para aprimorar a interação entre usuários e produtos utilizados em seu cotidiano na realização das Atividades de Vida Diária (AVDs). Neste trabalho, aborda-se uma das AVDs, o vestir. Gonçalves e Lopes (2006, p.23) acreditam que "os estudos ergonômicos contribuem com a área do vestuário em geral para auxiliar na evolução e solução dos projetos de produto de uso cotidiano [...] ao considerarem o bem-estar do homem na realização das tarefas no diaa-dia”. Para Silveira (2006), a ergonomia aplica-se de forma direta no caso de produtos do vestuário, fundamentando-se em outras ciências e envolvendo aspectos funcionais, psicológicos, de saúde, de segurança e a estética, o que demanda a participação de diferentes profissionais em seu projeto.

A ergonomia colabora também no aperfeiçoamento de dispositivos de TA, por meio do levantamento das necessidades, demandas e preferências dos usuários e da avaliação do uso. Essas tecnologias podem gerar atritos na sua interação com os usuários, principalmente porque eles possuem limitações funcionais. Paiva e Santos (2012, p.57) afirmam que "as limitações decorrentes de alterações sensório-motoras e percepto-cognitivas, bem como as disfunções crônico-degenerativas que se apresentam nos idosos compõem o alvo da ergonomia voltada à terceira idade", pois afetam a funcionalidade e o desempenho das atividades diárias dessas pessoas.

\subsection{Envelhecimento populacional}


A expectativa de vida da população mundial aumentará tanto nos países desenvolvidos quanto nos emergentes nos próximos anos. Em nível global, a prospecção é de alcance de 76 anos de idade entre 2045 e 2050 e 82 anos entre 2095 e 2100. No final do século, as pessoas dos países desenvolvidos poderão viver uma média de 89 anos, enquanto nas regiões em desenvolvimento esse número chegará a 81 . Inclusive nos países menos desenvolvidos a expectativa de vida aumentará, chegando a 70 anos entre 2045 e 2050 e 78 anos entre 2095 e 2100 (UNITED NATIONS, 2013).

No Brasil, a expectativa de vida ao nascer em 2000 era 69,83 anos, e sua projeção para 2030 é 78,64 anos de idade (IBGE, 2013), um aumento de quase dez anos. Ao longo de 30 anos, a esperança de vida ao nascer no país incrementou-se em média quatro meses e 15 dias anualmente (IBGE, 2010). De 2002 a 2011 o número de idosos no Brasil cresceu 34,7\%, enquanto a população total cresceu apenas $10,5 \%$. Prevê-se que entre 2011 e 2050 a população com mais de 60 anos ampliará de 10,25 para $29,75 \%$ a sua proporção em relação à população total, a qual crescerá apenas 10,44\%, passando de 194 para 215 milhões de habitantes (IBGE, 2008).

O aumento da longevidade da população do Brasil demanda investimentos e medidas eficazes que garantam a saúde física e mental e o bem-estar social da população idosa, tais como: construções adaptadas e compatíveis com suas limitações; vias públicas, logradouros e meios de transporte que não dificultem o seu direito de ir e vir; serviços de saúde com equipe médica especializada nas enfermidades que comumente a atingem (IBGE, 2010).

Dentre os aspectos físicos que sofrem impacto com o envelhecimento estão mudanças na pele, perda de altura e de flexibilidade, aumento do índice de massa corporal, perda de massa óssea, da área dos músculos esqueléticos e da força muscular (SPIRDUSO, 2005, MATSUDO; MATSUDO; BARROS NETO, 2000). A interação dos idosos com os produtos é influenciada por essas mudanças. O desenvolvimento de vestuário para esse público deve considerar os aspectos corporais que se modificam com o passar do tempo. Çivitci $(2004$, p.243) afirma que para os idosos a roupa representa um papel muito importante, devido às mudanças sociais e físicas decorrentes do envelhecimento. "O vestuário é ainda mais importante na velhice, pois os idosos desejam estabelecer novas conexões sociais, criar uma imagem e, especialmente, 
esconder as imperfeições que resultam das mudanças físicas causadas pela idade avançada."

Contudo, muitas roupas apresentam inadequações às características e necessidades da população idosa. Quando o vestuário comprado pronto não contempla as demandas dos idosos, estes podem utilizar estratégias para desempenhar a atividade de vestir diariamente. Nesse sentido, as TAs têm o potencial de minimizar as consequências que as limitações funcionais impõem aos idosos em seu dia a dia, proporcionando melhoria da qualidade de vida, conforme será apresentado na próxima seção.

\subsection{Tecnologias Assistivas}

Tecnologias Assistivas (TAs) são dispositivos, serviços, estratégias e práticas desenvolvidas e aplicadas para minimizar os problemas enfrentados por pessoas com limitações funcionais (COOK; POLGAR; HUSSEY, 2008). A ISO 9999:2011 define um produto assistivo como qualquer produto (incluindo dispositivos, equipamentos, instrumentos e software) produzido especialmente ou disponível de forma comum, usado por ou para pessoas com deficiência: para a participação; para proteger, apoiar, treinar, medir ou substituir funções, estruturas ou atividades do corpo; e para prevenir deficiências, limitações de atividade ou restrições de participação. No Brasil, o Decreto ${ }^{\circ}$ 5.296/2004 define ajudas técnicas como os produtos, instrumentos, equipamentos ou tecnologia adaptados ou especialmente projetados para melhorar a funcionalidade da pessoa portadora de deficiência ou com mobilidade reduzida, favorecendo a autonomia pessoal, total ou assistida.

Carriel (2007) afirma que as TAs são responsáveis pela inclusão social de indivíduos que apresentam dificuldades físico-motoras, pois melhoram a comunicação, a mobilidade, o controle do ambiente, as habilidades físicas e psicológicas e o desenvolvimento de outras atividades comuns do cotidiano. Farmer et al. (2014, p.982) afirmam que "talvez o maior benefício das soluções tecnológicas está em seu potencial para administrar a terapia de maneiras que são menos intensivas e mais convenientes

para os pacientes." Carriel (2007) ressalta que as TAs tornaram-se mais conhecidas devido a causas clínicas, porém seu uso é muito comum no cotidiano. Elas objetivam 
dar suporte a pessoas com deficiência para sua participação social e em sua vida diária (PLOS et al., 2012).

Um dispositivo de TA pode ser classificado como: para fim específico (exemplo: alimentador eletrônico) ou para fins gerais (exemplo: bastão utilizado com a boca para diferentes tarefas); de alta tecnologia (exemplo: cadeira de rodas elétrica) ou de tecnologia simples (exemplo: talheres modificados); hard, tangível, ou soft, intangível; comercial ou customizado; mínimo (provê assistência ao indivíduo para realizar determinadas tarefas) ou máximo (substitui significativamente uma função do indivíduo, como por exemplo os sintetizadores de voz); utensílio (não demanda o desenvolvimento e apreensão de um conhecimento para seu uso, como um par de óculos) ou ferramenta (exige o desenvolvimento de uma habilidade para o uso) (COOK; POLGAR; HUSSEY, 2008).

Todo dispositivo apresenta o risco de não ser utilizado ou de ferir o idoso caso: não seja prescrito corretamente, o paciente não seja suficientemente treinado para o uso ou não o deseje (BRUMMEL-SMITH; DANGIOLO, 2009). Segundo Plos et al. (2012), a aceitabilidade das TAs deve ser questionada, visto que cerca de um terço delas são abandonadas. Waldron e Layton (2008) afirmam que na maioria dos estudos que examinam a obtenção e a utilização dos dispositivos de TA são relatados altos índices de abandono ou de não uso do dispositivo. Para Wessels et al. (2003), os idosos adquirem deficiências gradualmente por um longo período, o que pode determinar o não uso de um dispositivo de TA por eles. Esses autores definem quatro grupos de fatores relacionados ao não uso de TAs: pessoais, relacionados ao dispositivo, relacionados ao ambiente e de intervenção. Sobre os fatores relacionados ao dispositivo, concluem que se o dispositivo é portátil, leve e de fácil uso será usado com maior frequência e durante mais tempo.

Brummel-Smith e Dangiolo (2009) afirmam que comumente os profissionais têm a preocupação de que um dispositivo irá aumentar a dependência ou reduzir a função. Plos et al. (2012) discutem as limitações de produtos especializados como as TAs: a falta de adequação entre oferta e procura, uma rede de distribuição especializada a qual envolve várias margens de lucro que impactam o preço do produto, a dificuldade de manter o serviço relacionado ao produto e dificuldades para comprar o produto. 
Bühler (1996) destaca a importância da avaliação com usuários finais como força motriz no desenvolvimento e utilização de novas tecnologias para pessoas com necessidades especiais. Para Robinson et al. (2013), designers, empresas e pesquisadores devem engajar-se em práticas participativas de desenvolvimento com os idosos para informá-los acerca das futuras TAs. Wessels et al. (2003, p.237) afirmam que a melhoria da qualidade e do serviço relacionado às TAs é responsabilidade, principalmente, dos fabricantes e fornecedores: "Design, montagem, entrega e ajustes ruins podem impedir uma utilização adequada. Além disso, formação ou instrução adequada e um manual do usuário são necessários."

Em pesquisa publicada na década de 1990 na Alemanha, Bühler (1996) afirma que o uso de TAs, apesar de apresentar problemas na prática, é muito comum. No Reino Unido, por outro lado, segundo Robinson et al. (2013), as TAs são subutilizadas no dia a dia, apesar de representarem uma solução para promover autonomia e independência aos idosos. Estes autores concluíram que os dispositivos mais utilizados por idosos de 85 anos de idade ou mais são as bengalas, seguidas por equipamentos para vestir, cozinhar e tomar banho. Neste trabalho, aborda-se a problemática da utilização das TAs por usuários idosos em uma das AVDs, o vestir.

\subsection{O vestir na vida do idoso}

O processo de envelhecimento faz emergir uma série de limitações funcionais nos indivíduos. "O bem-estar em idosos tem relação estreita com o equilíbrio entre as limitações impostas pela idade e as potencialidades individuais, que irá possibilitar o convívio com as perdas adquiridas na velhice.” (PAIVA; SANTOS, p.59). Esse é um fenômeno progressivo e degenerativo e cada pessoa envelhece de forma única. Todo o organismo envelhece: visão, audição, fala, movimentos de braços e pernas, capacidade de levantar objetos pesados ou de segurar objetos pequenos, dentre outras.

Costa, Nakatani e Bachion (2006) destacam que mesmo no envelhecimento saudável, a partir dos 80 anos se espera algum grau de comprometimento fisiológico na capacidade de realização das AVDs. Paiva e Santos (2012, p.59) afirmam que "o avanço da idade ocasiona dificuldades na realização de tarefas diárias dentro do contexto em que o idoso se encontra inserido." As AVDs são amplamente influenciadas pelo 
envelhecimento. Em alguns casos, o indivíduo perde a capacidade de executar tarefas que antes fazia sozinho e com facilidade. Banhar-se, por exemplo, é um desafio para uma pessoa que não possui os movimentos em um dos lados do corpo.

Brummel-Smith e Dangiolo (2009, p.64) afirmam que o vestir é influenciado por diversas doenças crônicas que afetam a vida no envelhecimento. "Muitos idosos com dificuldade de vestir-se encontram maneiras alternativas para compensar essa deficiência, tais como usar chinelos em vez de sapatos. Esse comportamento pode levá-los a ficar em casa e mais isolados."

Vestir-se, para fins de avaliação em saúde, é considerada uma Atividade Básica de Vida Diária (ABVDs), acompanhada de alimentar-se, banhar-se, arrumar-se, mobilizar-se e manter controle sobre suas eliminações, todas relacionadas ao autocuidado (DUARTE; ANDRADE; LEBRÃO, 2007). No Index de Independência nas Atividades de Vida Diária de Katz, a avaliação da função "vestir-se" considera: pegar as roupas (roupas íntimas, roupas externas, fechos e cintos) no armário e vestir-se. Calçar sapatos não é considerado. Os pacientes que recebem alguma assistência pessoal ou que permanecem parcial ou totalmente despidos são considerados dependentes (DUARTE; ANDRADE; LEBRÃO, 2007).

$\mathrm{Na}$ validação do instrumento proposto por Katz, observou-se que sujeitos que requeriam assistência em uma função apenas, essa era o banho; em duas funções, eram banhar-se e vestir-se; para três funções, eram banhar-se, vestir-se e ir ao banheiro. Para quatro funções, observavam-se as três primeiras mais transferência; para cinco, as quatro primeiras mais continência (DUARTE; ANDRADE; LEBRÃO, 2007). Portanto, vestir-se é uma atividade na qual os pacientes mais dependem de assistência.

Silva (2011) afirma que é possível obter avanços nos índices de funcionalidade nas AVDs, e especificamente no vestir, com a aplicação de poucos recursos financeiros. A autora propôs soluções que maximizaram o nível de independência dos sujeitos estudados, por exemplo aplicar texturas em etiquetas de roupas para facilitar o reconhecimento de suas cores por idosas com deficiência visual e modificar uma peça de vestuário íntimo, por meio de abertura frontal e fechamento com velcro e botões de pressão.

Uma série de habilidades é demandada para desenvolver essa atividade diária, o vestir: desde movimentos amplos dos braços e pernas até movimentos finos 
dos dedos para fechar botões. Brummel-Smith e Dangiolo (2009) afirmam que ajudas para vestir estão amplamente disponíveis, são simples de usar e relativamente baratas, porém é recomendável que antes de adotá-las seja feita a avaliação completa do paciente por um profissional qualificado, assim como acontece com outros dispositivos de assistência.

\section{Metodologia}

Cinco idosos participaram do teste após assinarem o Termo de Consentimento Livre e Esclarecido e o Consentimento para Fotografias, Vídeos e Gravações. O número de participantes foi definido com base em Nielsen (2000) e Nielsen e Landauer (1993). Esses autores demonstraram, por meio de um modelo matemático, que testes de usabilidade feitos com cinco usuários detectam cerca de $80 \%$ dos problemas dos produtos. Os participantes, selecionados de forma não probabilística, deveriam atender aos seguintes critérios: ter 60 anos de idade ou mais, não ter utilizado anteriormente o dispositivo a ser testado, saber ler e escrever.

O levantamento das TAs para vestir foi feito no Catálogo Nacional de Produtos de Tecnologia Assistiva, uma ferramenta web desenvolvida no âmbito do Ministério da Ciência, Tecnologia e Inovação que possibilita a realização de buscas sobre os produtos de TA fabricados ou distribuídos no Brasil. No Catálogo encontramse os produtos organizados de acordo com a classificação da ISO 9999:2007. Em "Produtos de apoio para cuidados pessoais e proteção", selecionando a opção "Produtos de apoio para vestir e despir", descrita como "equipamento que facilita o tirar ou o pôr a roupa e calçado", encontram-se dois produtos: na categoria "Produtos de apoio para calçar meias e collants", descrita como "dispositivos para auxiliar a pessoa a calçar soquetes, meias e collants", uma "Adaptação para Colocar Meia"; e na categoria "Ganchos para abotoar", descrita como "dispositivos para auxiliar a pessoa a abotoar e desabotoar roupas e calçado", um "Gancho para Abotoar Roupa".

O uso do gancho pressupõe vestir uma roupa anteriormente, seja uma calça ou um casaco, por exemplo. Por outro lado, a Adaptação para colocar meia pode ser testada sem a necessidade de executar uma tarefa previamente. Portanto, esse foi o dispositivo selecionado para o teste (Figura 1). A Adaptação para colocar meia testada neste estudo é apresentada na Figura 2. Ela possui $23 \mathrm{~cm}$ de comprimento e $20 \mathrm{~cm}$ de 
largura, além de duas alças com $85 \mathrm{~cm}$ cada. É forrada com tecido na cor azul, liso e brilhoso, tipo cetim, na parte interna, e felpudo branco na parte externa. Segundo seu fabricante, o dispositivo é um Soft sock aid. Um folheto com as instruções para uso acompanha o produto (Figura 3).

De acordo com a classificação proposta por Cook, Polgar e Hussey (2008), apresentada na seção 2.3 deste artigo, a Adaptação para colocar meia pode ser considerada um utensílio comercial, com fim específico, tecnologia simples, mínima, do tipo hard.

Figura 1: Demonstração de uso da adaptação para colocar meia

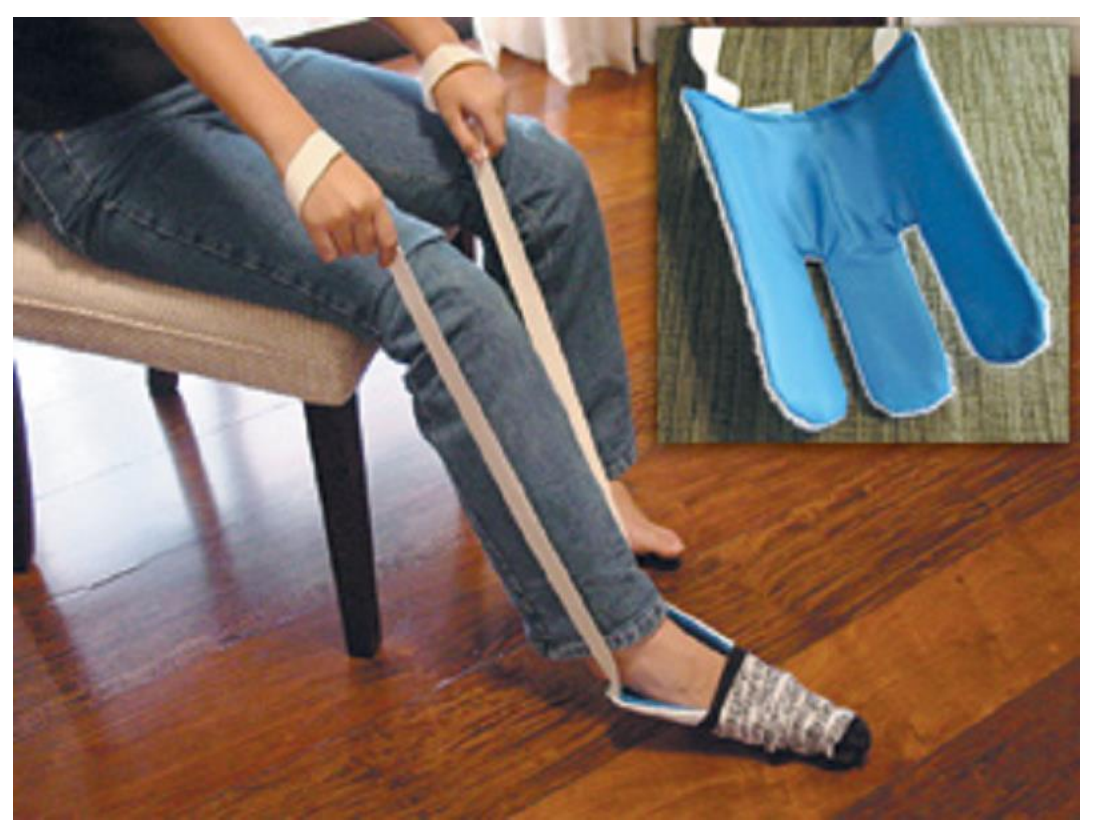

Fonte: http://www.mnsuprimentos.com.br/menu/?p=450\#3 
Figura 2: Visão externa (acima), com medidas gerais, e visão interna (abaixo) da Adaptação para colocar meia

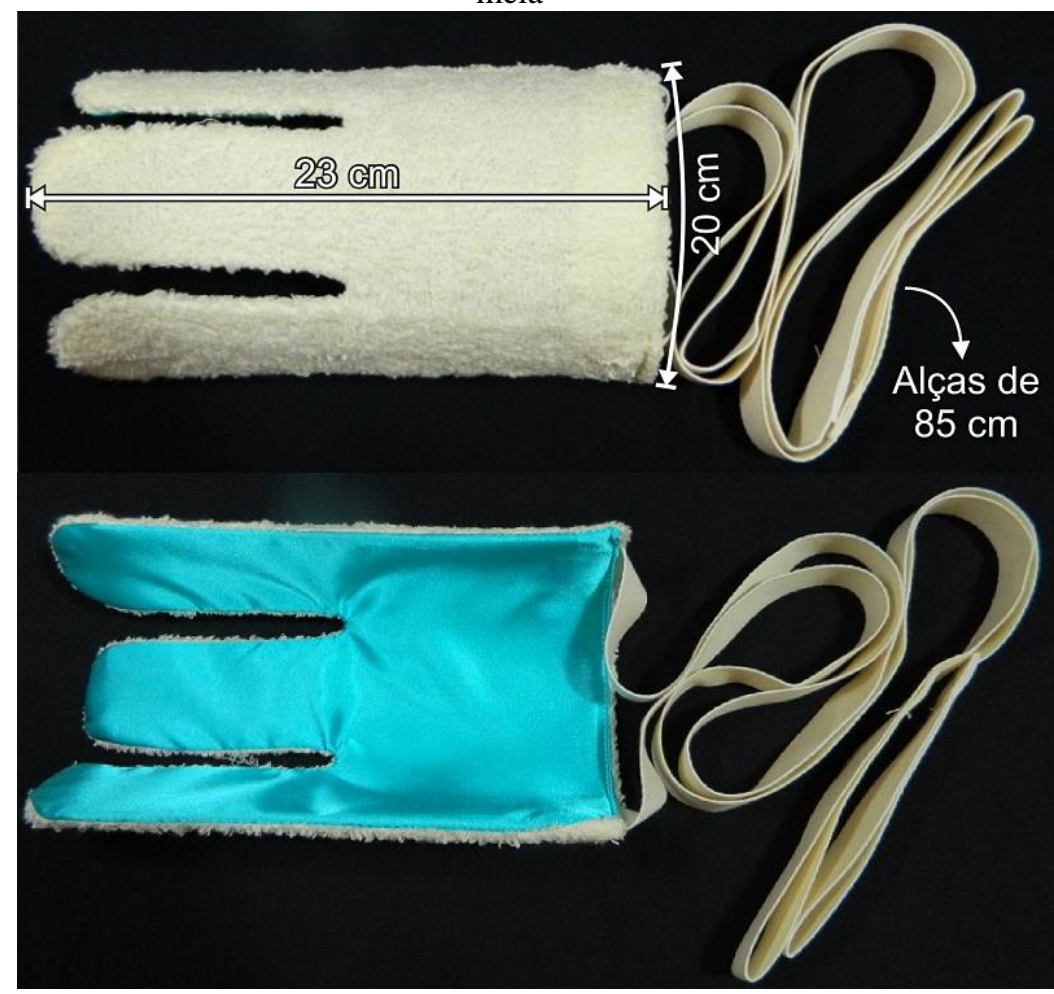

Fonte: autores

Figura 3: Folheto de instruções para o uso da adaptação para meias 28600 - ADAPTAÇÃO PARA MEIAS

Féta de plástico fexivel, é de fácil manuseio mesmo para quem use somente uma das mãos. É compacta, leve e pode ser lavada à mâo.

\section{INSTRUÇOES}

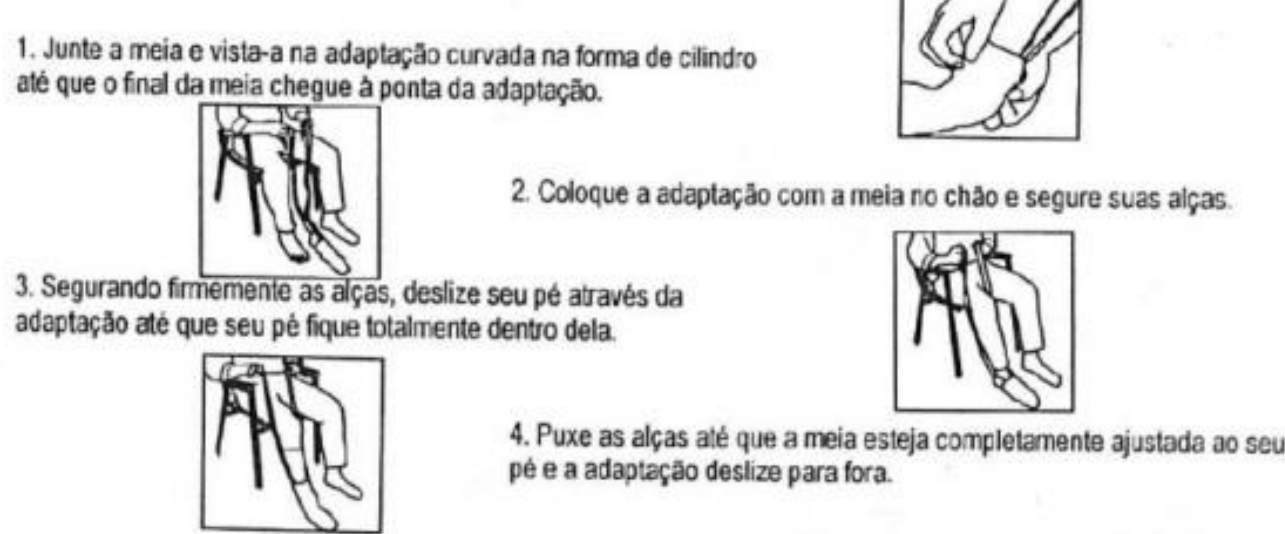

Fonte: entregue juntamente com o produto pelo distribuidor no Brasil

As meias utilizadas durante o teste (Figura 4), fornecidas pelos pesquisadores, são do tipo clássica masculina, de tamanho único, as quais servem para 
calçados de 37 a 44. São feitas em material sintético, 100\% poliamida. Possuem punho soft e calcanhar verdadeiro, característica que proporciona maior ajuste aos usuários, segundo o fabricante.

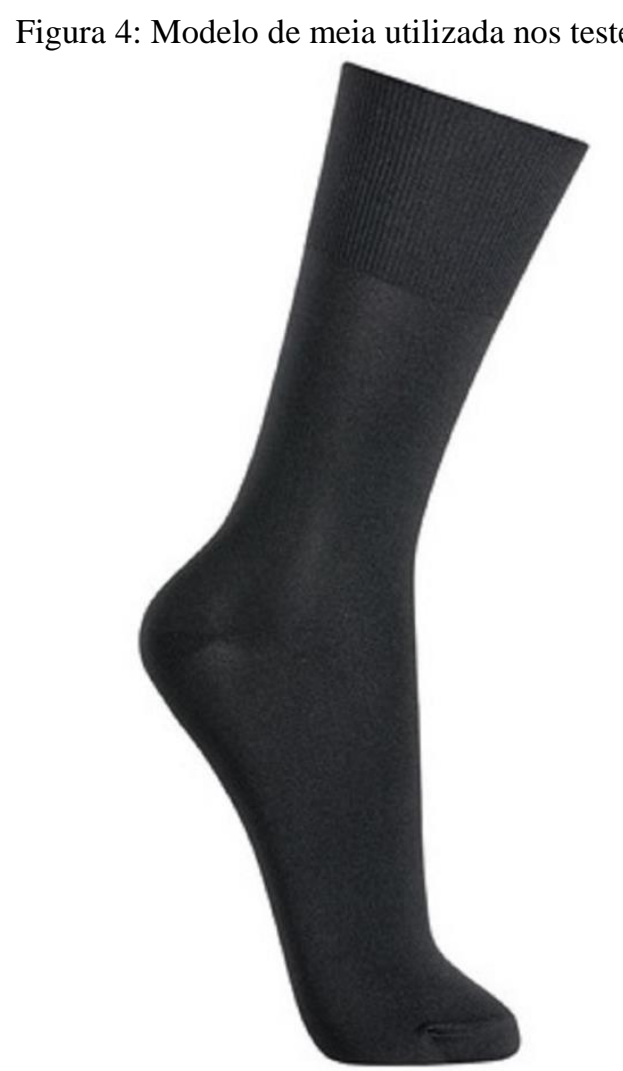

Fonte: http://site.lupo.com.br/produtos/meia/masculino-06/classica2/

O teste foi composto de três etapas: 1) coleta de dados relativos a demandas, necessidades e problemas de vestuário; 2) realização da tarefa de vestir um par de meias utilizando a Adaptação para colocar meia; e, 3) avaliação do uso do dispositivo.

Após consentirem em participar do estudo, os participantes responderam ao questionário sobre demandas, necessidades e problemas de vestuário dos idosos (Quadro 1), traduzido de Çivitci (2004) e composto de duas partes: 1) informações gerais sobre a pessoa; e 2) mudanças no corpo devido à idade avançada e os seus efeitos sobre a preferência do vestuário, as exigências e as necessidades da pessoa. Depois de traduzir o questionário, foi realizada uma avaliação da equivalência semântica e idiomática entre as versões original e traduzida do instrumento. Além disso, algumas adaptações para aplicá-lo no Brasil foram efetuadas: 1) inserir mais um item na questão sobre a idade, visto que no Brasil são consideradas idosas as pessoas com idade igual ou 
superior a 60 anos, de acordo com o Estatuto do Idoso (Lei $\mathrm{n}^{\mathrm{o}}$ 10.741/2003); 2) modificar a quarta questão, relativa à renda mensal do participante, pois a questão original apresentava valores em liras turcas. Neste caso, optou-se por uma questão aberta, conforme sugerem Veras e Dutra (2008).

Após responderem o primeiro questionário, os participantes foram orientados a ler as instruções de uso do dispositivo fornecidas pelo distribuidor e, em seguida, utilizá-lo para calçar um par de meias. Realizada a tarefa, foi aplicado o segundo questionário, adaptado de Melo (2000), a fim de avaliar a percepção dos participantes após o uso do dispositivo (Quadro 2).

Quadro 1: Questionário sobre demandas, necessidades e problemas de vestuário dos idosos

1. Quantos anos você tem?
( ) $60-65$
( ) $66-70$
( ) $71-75$
( ) $76-80$
( ) 81 ou mais

2. Quantos quilos você pesa?

( ) Menos de $60 \mathrm{~kg}$

( ) $61-70 \mathrm{~kg}$

( ) $71-80 \mathrm{~kg}$

( ) $81 \mathrm{~kg}$ ou mais

3. Quantos reais você ganha mensalmente? $\mathrm{R} \$$

4. Que tipos de mudanças vêm ocorrendo em sua estrutura corporal devido ao envelhecimento?
( ) Variações de peso
( ) Diminuição de altura
( ) Deformação nos ossos
( ) Outras
( ) Todas elas

5. Você tem dificuldade para movimentar-se?

( ) Dificuldade na utilização dos braços

( ) Dificuldade na utilização das pernas

( ) Dificuldade na utilização dos dedos

( ) Outras

( ) Sou saudável

6. Você tem alguma doença que afeta as atividades de vestir e despir?

( ) Doença muscular

( ) Doença nas articulações

( ) Doença neurológica

( ) Outras

( ) Sou saudável

7. Por quanto tempo você usa suas roupas?

( ) Até que se desgastem

( ) Até cansar delas
10. Que tipo de roupas você prefere normalmente?

( ) Calça e camisa

( ) Roupas esportivas

( ) Outro

11. Você precisa de alguma ajuda para vestir e despir?

( ) Algumas de minhas roupas

( ) Todas as minhas roupas

( ) Não preciso

12. Você precisa de alguma roupa especial?

( ) Sim

( ) Não

13. Que tipo de necessidade básica suas roupas devem facilitar?

( ) Comer

( ) Usar o banheiro

( ) Limpeza diária

( ) Outra ....

( ) Todas as minhas necessidades

14. De que maneira você compra suas roupas?

( ) Prontas e depois faço alterações

( ) Encomendo roupas sob medida

( ) Às vezes compro roupas prontas, às vezes

encomendo roupas sob medida

( ) Outra

15. Você prefere roupas feitas com qual tipo de tecido?

( ) Natural

( ) Sintético

( ) Outro

( ) Qualquer um deles

16. Você tem algum problema com suas roupas compradas prontas?

( ) Não se ajustam ao meu tamanho

( ) Acho os estilos inadequados

( ) Acho os preços muito altos 
( ) Até saírem de moda
( ) Outra .................................

8. Quanto tempo você leva para se vestir e despir?

( ) 5-7 minutos

( ) 8-10 minutos

( ) 11-13 minutos

( ) 14 minutos ou mais

9. Qual sua opinião sobre os preços das roupas?

( ) Baratos

( ) Normais

( ) Caros

( ) Muito caros
( ) Outros
( ) Não tenho problemas

17. Por quais características você procura ao comprar uma peça de roupa?

( ) Vestir bem

( ) Facilidade de manutenção

( ) Preço

( ) Moda

( ) Outras

18. Você tem problemas relacionados com a roupa em que aspectos?

( ) Dificuldade para vestir e despir

( ) Limpeza diária

( ) Usar o banheiro

( ) Uso em geral

( ) Outros

Fonte: Traduzido de Çivitci (2004) e adaptado para uso no Brasil pelos autores

\section{Você gostaria de usar este produto} frequentemente?

Sim ( ) Não ( ) Por quê?

2. Na sua opinião, este produto é complexo? Sim ( ) Não ( ) Por quê?

3. Na sua opinião, este produto é fácil de usar? Sim ( ) Não ( ) Por quê?

4. Na sua opinião, você precisaria da ajuda de outra pessoa para conseguir usar este produto?

Sim ( ) Não ( ) Por quê?

5. Na sua opinião, a maioria das pessoas aprende a usar este produto rapidamente?

Sim ( ) Não ( ) Por quê?
6. Você tem confiança no desempenho deste produto?

Sim ( ) Não ( ) Por quê?

7. Na sua opinião, você precisa aprender bastante antes de realmente usar este produto?

Sim ( ) Não ( ) Por quê?

8. Quais vantagens você destaca na utilização deste produto?

9. Quais desvantagens você destaca na utilização deste produto?

10. Qual a sua percepção geral em relação ao produto?

11. Por favor, deixe aqui seus comentários adicionais:

Fonte: adaptado de Melo (2000)

Durante a realização das três etapas do teste, os pesquisadores realizaram anotações com base em observações diretas e nos comentários dos participantes. Além disso, foram feitos registros fotográficos da segunda etapa, permitindo posterior observação indireta para análise dos dados. A análise foi feita principalmente de forma qualitativa com base nas respostas dos participantes aos questionários, nas imagens coletadas e nas anotações dos pesquisadores. 


\section{Resultados}

\subsection{Dados gerais da amostra}

Quatro participantes do estudo têm idade entre 60 e 65 anos e um tem entre 71 e 75 anos. Apenas um dos participantes tem entre 71 e $80 \mathrm{~kg}$, o restante pesa $81 \mathrm{~kg}$ ou mais. Sua renda mensal é superior a $\mathrm{R} \$ 4.000,00$, chegando, em um dos casos, a cerca de $\mathrm{R} \$ 12.000,00$. Em relação às mudanças que vêm ocorrendo em sua estrutura corporal devido ao envelhecimento, os cinco participantes assinalaram apenas a opção variações de peso.

\subsection{Demandas, necessidades e problemas de vestuário dos idosos}

Quando questionados sobre a existência de dificuldades para movimentarse, quatro participantes do estudo afirmaram ser saudáveis. Um deles complementou que tem dificuldade na utilização dos dedos e outro na utilização dos braços. Este último tem doenças nas articulações que afetam as atividades de vestir e despir. Os outros quatro não apresentam doenças que afetam essas atividades.

Quanto ao tempo que levam para se vestir e despir, três participantes levam de 5 a 7 minutos, um de 8 a 10 minutos e o quinto de 11 a 13 minutos. Este último, contudo, após finalizar o teste, comentou que considerou que o vestir compreende desde a escolha das peças até vesti-las propriamente.

Em relação a quanto tempo usam as roupas, apenas dois itens foram citados: até que se desgastem (citado por quatro participantes) e até cansar delas (citado por dois participantes). Nenhum participante afirmou utilizar suas roupas até saírem de moda. Essa despreocupação com a moda é corroborada pelas respostas à questão relacionada às características procuradas pelos participantes ao comprarem roupas: a opção moda não foi citada por nenhum dos participantes.

Os participantes do estudo preferem roupas do tipo calça e camisa, as quais são compradas prontas e alteradas posteriormente. Três participantes afirmaram que as alterações são necessárias somente na altura das pernas. Quatro participantes afirmam não ter problemas com as roupas compradas prontas, porém para um deles as roupas não se ajustam ao seu tamanho. Quando questionados quanto a que aspectos causam 
problemas em sua relação com as roupas, três participantes afirmaram não ter problemas, enquanto dois declararam ter problemas no uso geral.

Há preferência por tecidos naturais em três casos, sendo que os outros dois participantes optam tanto por tecidos naturais quanto sintéticos. Quanto aos preços das roupas, quatro participantes os consideram normais, enquanto um as considera caras. Vestir bem é uma característica procurada por quatro participantes ao comprarem suas roupas, seguida por preço, citado por três participantes. Nenhum dos participantes citou a facilidade de manutenção e a moda como uma característica demandada.

Os participantes do estudo não precisam de ajuda para se vestir e despir, tampouco necessitam de roupas especiais. Quatro deles afirmaram que as roupas devem facilitar todas as suas necessidades básicas, e o outro não tem nenhuma necessidade básica que deva ser facilitada pelas roupas que usa.

\subsection{Avaliação da Adaptação para colocar meia}

Após realizar a tarefa de vestir um par de meias utilizando a adaptação para colocar meia, os participantes responderam a um questionário para avaliação do uso do dispositivo. Três deles afirmaram que não gostariam de usar o produto com frequência, um deles justifica que não tem necessidade. Um participante afirmou que gostaria de utilizar o dispositivo frequentemente, pois, segundo ele, "a ideia é boa", apesar de necessitar de aperfeiçoamentos. Para este participante, o produto não é complexo e é fácil de usar, "muito prático". Outros dois participantes têm a mesma opinião, um deles afirma que é "fácil de adaptar-se" e o outro, apesar de considerar que o produto não é complexo, relatou não ter utilizado de forma adequada. Dois participantes consideraram o produto complexo "devido ao manual deficiente; dificuldade na colocação da meia no dispositivo", segundo um deles. Esse mesmo participante afirmou que o produto é fácil de usar "se a pessoa não tiver dificuldade para se flexionar" e não é fácil de usar caso o usuário tenha limitações nos movimentos.

Todos os participantes afirmaram que não precisariam da ajuda de outra pessoa para conseguir usar o dispositivo testado. Para um deles o produto "é de fácil manuseio", enquanto que outro participante afirmou que apenas é possível usá-lo sem ajuda se o manual for melhor ilustrado. Corroborando essa questão, os cinco participantes acreditam que a maioria das pessoas aprende a usar o produto 
rapidamente, porém um deles reafirmou que isso depende de a pessoa entender como usá-lo, referindo-se ao manual, considerado pouco ilustrado por esse participante.

Os participantes acreditam que não é preciso aprender bastante antes de realmente usar o produto, contudo, dois deles ressaltaram novamente a questão do manual: "precisa melhorar as instruções, ao invés de desenhos colocar fotos"; "falta manual ilustrado". Apenas um participante afirmou não ter confiança no uso do produto. Para os demais, ele é "simples e seguro" e "precisa de mudança, exemplo: maior flexibilidade".

As vantagens destacadas por um participante em relação ao produto testado são conforto e independência no vestir-se, considerando que o usuário tenha limitações. Outro participante afirmou que o dispositivo facilita a vida do idoso que tem problemas de flexibilidade. Ainda são vantagens destacadas pelos participantes: "não ter que cruzar as pernas quando coloca as meias" e "você o usa mesmo sentado".

Em contraponto, foram elencadas as seguintes desvantagens: desconfortável, muito rígido e possibilita uma acomodação do usuário que possui limitação de flexibilidade, levando-o a não se exercitar nas atividades da vida diária. Além disso, um dos participantes destacou como desvantagem as pessoas terem de perceber a utilidade do produto.

A percepção geral do produto por parte de quatro participantes foi positiva: "a ideia é interessante para ajudar pessoas que possuem essa limitação"; "me parece muito útil, prático"; "acredito que tenha utilidade"; "acredito ser de ótima valia para quem tem problemas de agachar-se”. Para um dos participantes a percepção geral do produto foi ruim.

Quatro participantes fizeram comentários adicionais: 1) "o produto tem proposta válida/interessante, mas que não conduza os usuários para uma acomodação"; 2) "o produto precisa de mudanças como maior flexibilidade para passar no calcanhar, no mais a ideia me parece muito boa"; 3) "é fácil de aprender e acredito que tenha utilidade para uma pessoa idosa que tenha dificuldade de movimentos"; 4) "o produto demonstra ter qualidades que poderão ajudar em muito pessoas idosas com problemas musculares".

A seguir é apresentado um breve relato acerca dos testes realizados com base nas percepções dos pesquisadores e nos comentários feitos pelos participantes. 


\subsubsection{Participante 1}

O primeiro participante tem 63 anos de idade. Logo no início do teste, ele teve dúvida quando a ter que puxar toda a meia para o dispositivo ou deixar a ponta dela solta. Segundo ele, "tem que fazer treinamento" para usar o produto e o fato de a meia utilizada no teste ser nova pode influenciar no uso do dispositivo, principalmente no momento de vesti-la no produto.

Esse participante não conseguiu vestir corretamente a meia, conforme pode ser visto na Figura 5. Uma de suas sugestões foi fazer o folheto de instruções de uso com fotos de pessoas utilizando o produto e pequenas legendas. Seu principal problema em relação às instruções foi no passo número um, o qual, segundo ele, deveria ter uma figura mais clara, pois "está muito complicado". O tempo total do teste foi aproximadamente 40 minutos, e o tempo utilizado para vestir o par de meias foi aproximadamente 6 minutos.

Figura 5: Participante 1 realizando a tarefa de vestir o par de meias utilizando o dispositivo avaliado
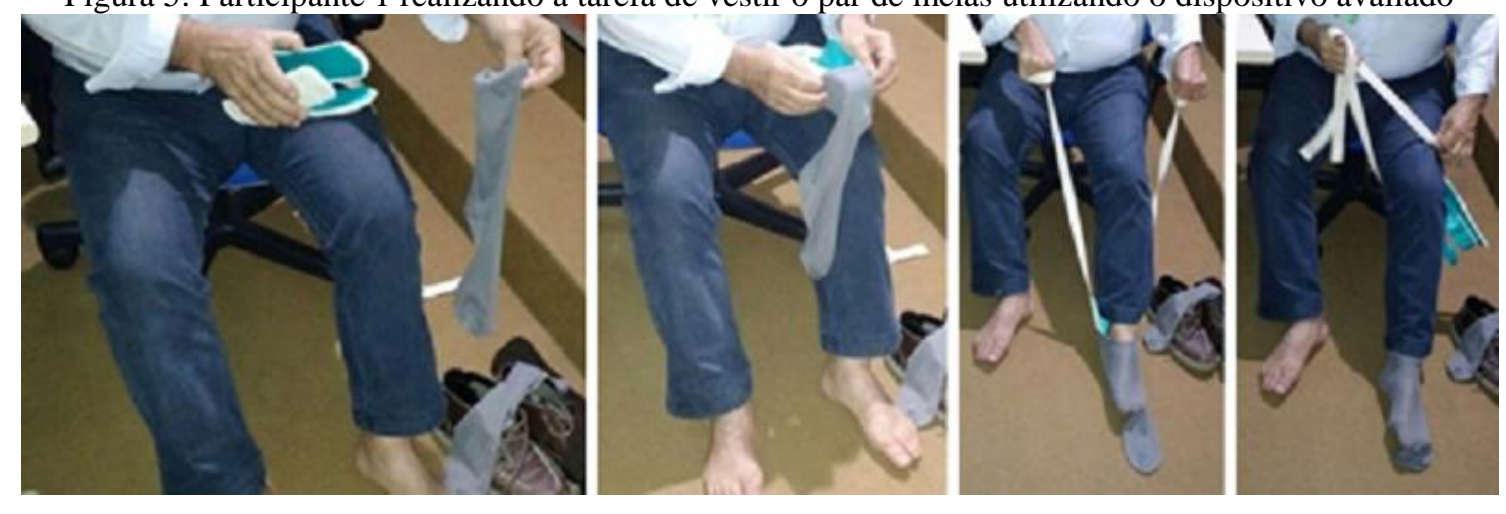

Fonte: autores

\subsubsection{Participante 2}

O participante 2 tem 65 anos de idade. Decorridos quase três minutos do começo da execução da tarefa, ele pareceu incomodado e expressou "não está certo isso", referindo-se à maneira como havia colocado a meia no dispositivo, conforme pode ser visto na primeira fotografia da Figura 6. Ao tentar vestir a segunda meia, o participante realizou a tarefa até o terceiro passo, porém não conseguiu puxar a Adaptação para retirá-la do pé. Sendo assim, abaixou-se para retirá-la com as mãos e iniciou novamente a tarefa. Devido a essa dificuldade, o participante 2 fez uma sugestão 
para melhoria do produto: fazê-lo mais flexível no sentido do comprimento para que o calcanhar deslize e se acomode com mais facilidade.

Este idoso, assim como o participante 1, sugeriu que o folheto de instruções seja feito com fotografias de uma pessoa utilizando o produto. Segundo ele, "a ideia é boa, mas tem que fazer funcionar". Na Figura 6 pode-se ver a realização da tarefa pelo participante 2, o qual utilizou aproximadamente 35 minutos para realizar todo o teste e aproximadamente 11 minutos para vestir o par de meias.

Figura 6: Participante 2 realizando a tarefa de vestir o par de meias utilizando o dispositivo avaliado
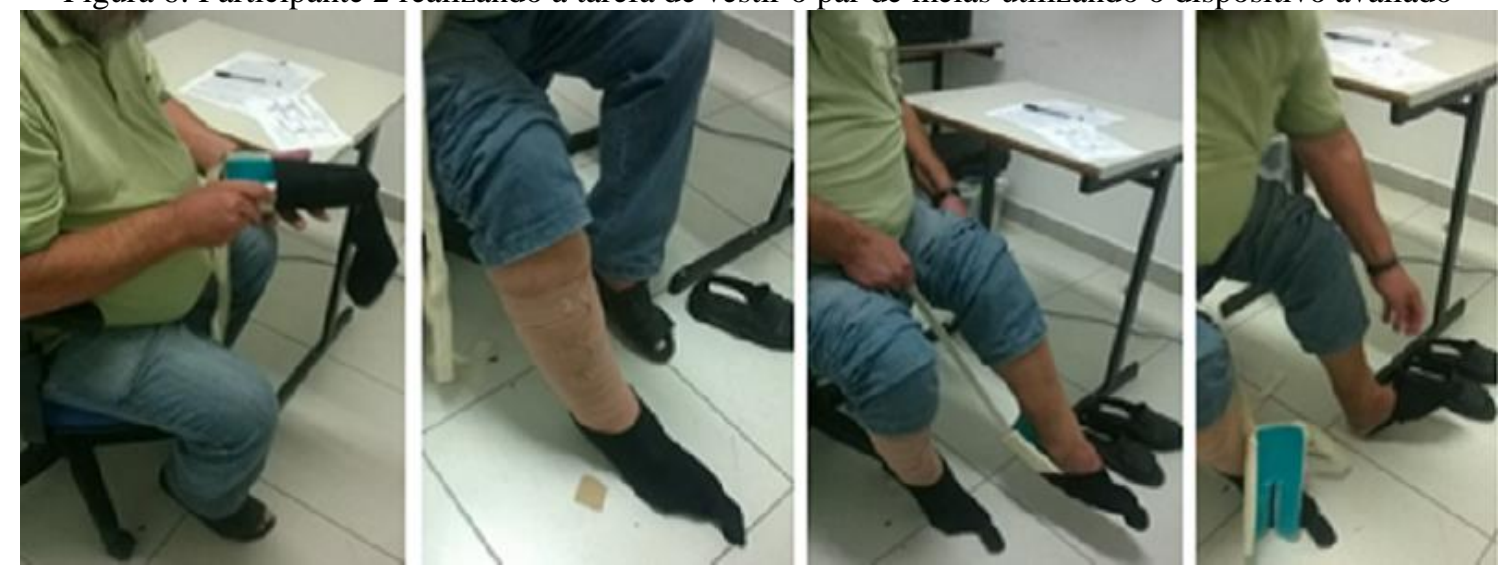

Fonte: autores

\subsubsection{Participante 3}

O participante 3, que tem 60 anos de idade, teve dúvidas em relação a alguns termos utilizados durante o teste. Por exemplo, questionou o que é uma roupa especial. Outra dúvida foi em relação à "ponta da adaptação" e ao "final da meia", citados no folheto de instruções. Segundo ele, esses termos geram confusão no entendimento. Este idoso teve uma percepção ruim do produto e afirmou que é mais trabalhoso vestir as meias usando o dispositivo do que da forma convencional. Segundo ele, é mais fácil tirar a Adaptação do pé puxando as alças para trás da perna do que para cima, conforme sugere a imagem do folheto de instruções.

Uma sugestão para melhoria do produto trazida por esse participante foi revestir a parte interna com um tecido acolchoado, que proporcione maior conforto no uso. Além disso, afirmou que o dispositivo é muito rígido e que parece que os pés ficam em contato direto com o plástico, devido à espessura do tecido de forro. 
O tempo total do teste com o participante 3 foi bastante inferior aos anteriores: 4 minutos para vestir o par de meias e 10 minutos para realizar todo o teste, aproximadamente. Na Figura 7, são apresentados os registros desse teste, nos quais é possível perceber que o participante não conseguiu vestir as meias de forma completa com a utilização da Adaptação.

Figura 7: Participante 3 realizando a tarefa de vestir o par de meias utilizando o dispositivo avaliado
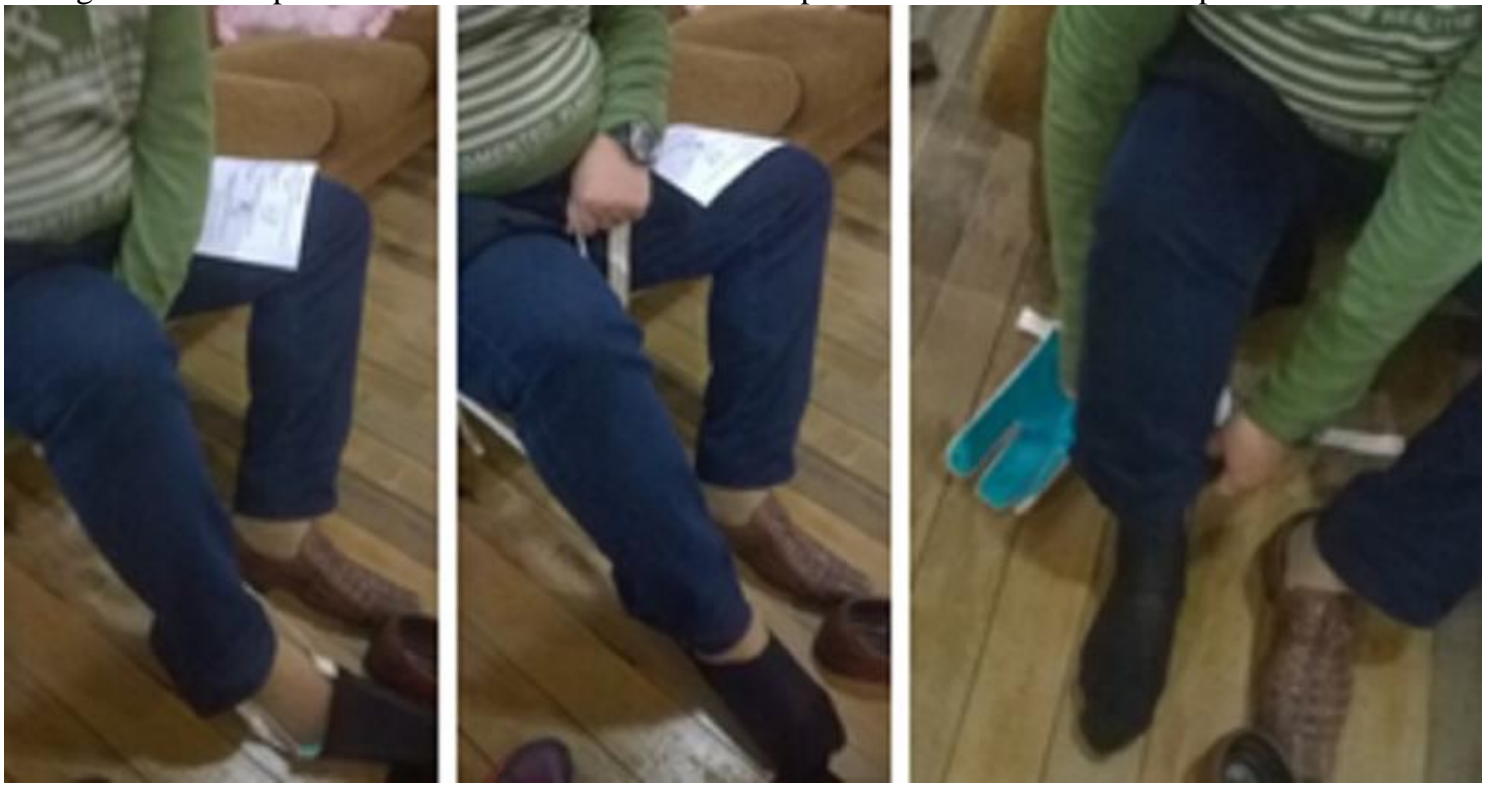

Fonte: autores

\subsubsection{Participante 4}

O participante 4 tem mais de 70 anos de idade. Durante o teste, ele levantou os pés diversas vezes para vestir o par de meias, como é possível perceber na Figura 8. Assim como o participante 3, ele afirmou que foi mais difícil vestir as meias utilizando a Adaptação do que as vestindo da forma convencional. Os pesquisadores questionaram se isso poderia ter ocorrido devido à forma como as instruções são apresentadas no folheto e o participante admitiu ter lido apenas o primeiro passo das instruções antes de realizar a tarefa, e por isso, segundo ele, utilizou o produto de forma "errada": "não li as instruções direito, acho que foi isso.” A Figura 8 demonstra a realização do teste com o participante 4, que utilizou aproximadamente 5 minutos para vestir o par de meias e 20 minutos para realizar todo o teste. 
Figura 8: Participante 4 realizando a tarefa de vestir o par de meias utilizando o dispositivo avaliado
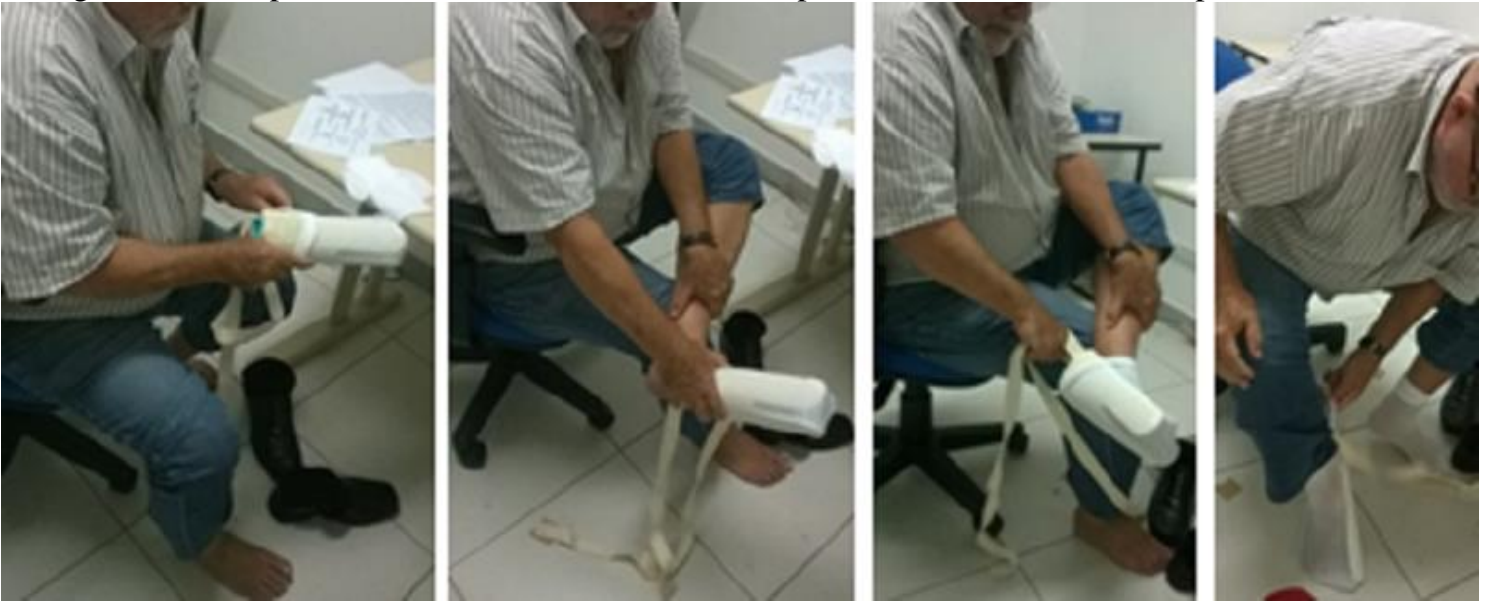

Fonte: autores

\subsubsection{Participante 5}

O participante 5, com 62 anos de idade, conseguiu utilizar o dispositivo com facilidade, sendo que para vestir o par de meias foram necessários pouco mais de três minutos. Ele afirmou após responder ao questionário de avaliação do uso que o produto é bom, bem prático. A Figura 9 apresenta a realização do teste com o participante 5, que teve duração total de 15 minutos.

Figura 9: Participante 5 realizando a tarefa de vestir o par de meias utilizando o dispositivo avaliado
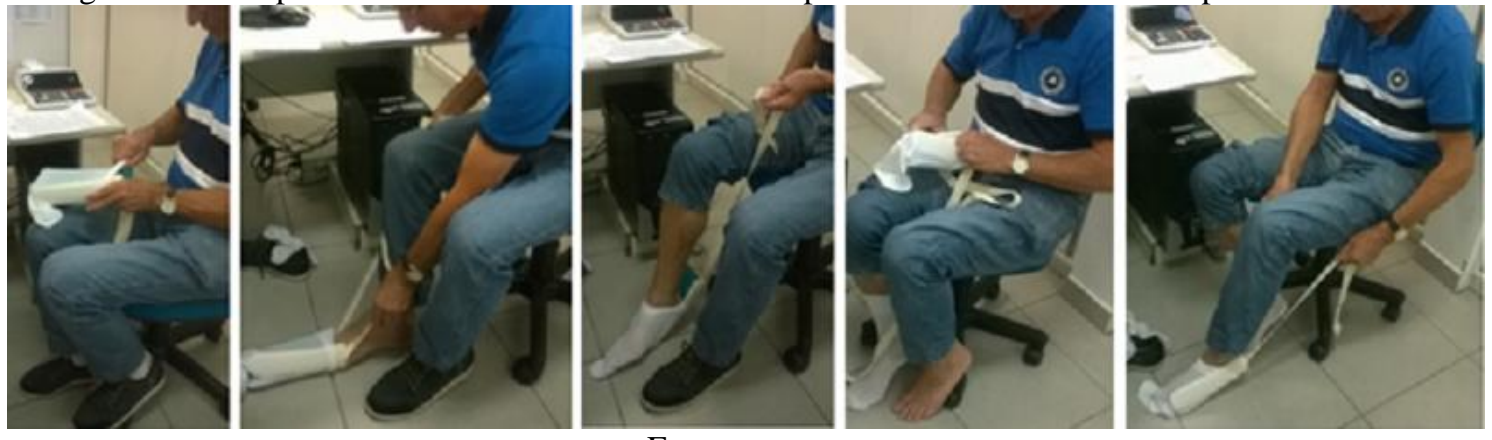

Fonte: autores 


\subsubsection{Percepções gerais dos pesquisadores}

Durante os testes, quando os participantes vestiram a meia no dispositivo, o espaço para o pé tornou-se estreito, dificultando o uso, o que pode ter relação com o fato de a meia ser nova ou de ter cano longo. Porém, não são apresentadas essas condições de restrição do uso no folheto de instruções da Adaptação testada. A meia, segundo seu fabricante, possui punho soft, o que deveria facilitar o vestir.

Em relação ao tempo necessário para realizar os testes, o tempo médio utilizado para vestir o par de meias foi de cinco minutos e para todo o teste, incluindo o preenchimento dos questionários, foi de 23 a 24 minutos.

\subsection{Avaliação dos instrumentos do estudo}

Por meio da realização dos testes, foi possível avaliar os questionários utilizados e destacar possíveis aprimoramentos para futuros estudos. No questionário sobre as demandas, necessidades e problemas de vestuário, traduzido de Çivitci (2004), um dos participantes não compreendeu o termo limpeza diária, traduzido do inglês daily cleaning. Segundo ele, o termo pode significar asseio pessoal ou limpeza doméstica. Para resolver esse problema, sugere-se substituir limpeza diária por fazer tarefas domésticas, apresentado no trabalho de Costa, Nakatani e Bachion (2006).

Ainda nesse questionário, sugere-se inserir, respectivamente, nas questões 13 e 18 as opções "Nenhuma" e "Não tenho", sugestão feita por dois participantes. A questão nove também suscitou dúvidas nos participantes. Dois deles comentaram que sua opinião sobre os preços das roupas depende muito da referência, ou seja, de que tipo de roupas se está tratando. Um participante comentou: "se for só de marca é caro, muito caro". Uma sugestão para essa pergunta seria questionar a faixa de preços das roupas adquiridas pelos participantes, com que frequência compram roupas e se essa frequência está relacionada ao preço das roupas.

A questão número oito, segundo um dos participantes, deve deixar claro se se refere ao tempo que a pessoa leva para vestir e despir as roupas, tendo-as todas escolhidas e a sua disposição, ou se nesse tempo está se considerando também a escolha das roupas a vestir. Esse participante sugeriu o seguinte enunciado para a questão: Dispondo de todas as roupas a sua frente, quanto tempo você leva para vestir-se? 
Contudo, considerando a descrição proposta no Index de Independência nas Atividades de Vida Diária de Katz, vestir-se considera: pegar as roupas no armário e vestir-se.

Ainda no questionário adaptado de Çivitci (2004), pode-se aprimorar a questão 14, inserindo na primeira opção de resposta (Prontas e depois faço alterações) a possibilidade de o participante especificar quais alterações realiza em suas roupas compradas prontas. Três participantes relataram, enquanto respondiam a essa questão, que a única alteração que realizam é o ajuste do comprimento das calças.

No questionário para avaliação após o uso do produto (adaptado de Melo, 2000), as questões dois e três, para um dos participantes, são repetitivas. Em uma delas, é perguntado ao participante se o produto é complexo, e na outra se ele é fácil de usar. Faz-se necessário aplicar o questionário com um número maior de participantes para verificar se essa percepção aparece em demais casos.

\section{Discussões}

Nesta seção, os resultados são discutidos com a literatura pertinente e considerando as limitações do trabalho. O estudo foi realizado com um grupo de cinco homens, com no mínimo 60 anos de idade, que sabem ler e escrever e que não haviam utilizado o produto antes do teste. As discussões e conclusões são aplicadas a este perfil.

Com base nos resultados dos testes realizados, pode-se corroborar o que Spirduso (2005) afirma em relação ao aumento do índice de massa corporal como um dos aspectos físicos que sofrem impacto com o envelhecimento. Todos os participantes citaram apenas a variação de peso como a mudança que vêm ocorrendo em sua estrutura corporal. No estudo de Çivitci (2004), essa também foi a alteração mais citada, representando $39,2 \%$ da amostra.

Quatro dos cinco participantes utilizam suas roupas até que elas se desgastem, e dois até cansarem delas. Çivitci (2004) encontrou resultados parecidos em sua amostra: 69,2\% afirmaram usar as roupas até se desgastarem e 22,5\% até cansarem delas, sendo estes os itens mais citados.

Enquanto 60,8\% dos participantes da pesquisa de Çivitci (2004) preferem roupas do tipo calça e camisa, neste trabalho $100 \%$ têm essa preferência. Quanto aos tipos de tecidos, foram encontrados resultados parecidos nos dois estudos: o percentual dos que preferem tecidos naturais é de 68,3\% em Çivitci (2004) e de 60\% neste 
trabalho, seguidos em ambos os trabalhos por aqueles que não têm preferência por um dos tipos. Mais da metade da amostra de Çivitci (2004) procura por facilidade de manutenção ao comprarem roupas, característica que não foi citada pelos participantes desta pesquisa, na qual as características mais recorrentes são: vestir bem e preço.

Quanto ao dispositivo testado, pode-se inferir, com base em Wessels et al. (2003), que a chance de ele ser usado com maior frequência e durante mais tempo é grande, visto que os participantes afirmaram que não precisariam da ajuda de outra pessoa para usá-lo, acreditam que a maioria das pessoas aprende a usá-lo rapidamente e que não é preciso aprender bastante antes do uso. A avaliação do produto indica que ele é de fácil uso.

Por outro lado, a maioria dos participantes não conseguiu vestir as meias até o final. Isso pode ter relação com o fato de eles não conhecerem o produto antes do teste. Porém, também podem ser citadas as limitações do folheto de instruções fornecido pelo distribuidor. Segundo os participantes, o produto tem um manual deficiente, que deveria ser mais ilustrado. $\mathrm{O}$ abandono das TAs relaciona-se com a falta de treinamento para o uso (BRUMMEL-SMITH; DANGIOLO, 2009) e o manual é uma das ferramentas envolvidas nesse processo. Wessels et al. (2003) destacam a importância da instrução e do manual do usuário serem adequados para proporcionar uma melhor experiência do usuário com a TA. Instruções falhas podem impedir o uso de um dispositivo de TA desde o início, fazendo com que o usuário não possa perceber as vantagens de inclui-lo em suas AVDs.

A questão levantada por Brummel-Smith e Dangiolo (2009) relacionada à preocupação dos profissionais de que um dispositivo irá aumentar a dependência ou reduzir a função foi comentada também por um dos participantes: "o produto tem proposta válida/interessante, mas que não conduza os usuários para uma acomodação". No entanto, é um produto que proporciona independência do usuário na realização da atividade de vestir, observação feita também por um participante deste estudo.

Quanto às limitações do produto testado, destaca-se a dificuldade para comprá-lo, também citada por Plos et al. (2012), visto que não foi encontrado na cidade em que se realizou o estudo, sendo necessário adquiri-lo em uma loja virtual. Foram citadas pelos participantes limitações relacionadas à rigidez do produto e, principalmente, ao seu manual. 
A pesquisa demonstrou a importância de envolver os usuários no desenvolvimento dos produtos de TA, conforme afirmado por Bühler (1996) e Robinson et al. (2013). Além disso, nenhum dos participantes conhecia o produto, assim como ocorre no Reino Unido, onde as TAs são subutilizadas no dia a dia, segundo Robinson et al. (2013).

\section{Conclusões}

Devido ao tamanho da amostra, os resultados deste estudo não podem ser generalizados, contudo seu caráter experimental e preliminar permitiu uma análise qualitativa que levanta questionamentos e sugestões para trabalhos futuros. Considerase que o objetivo foi alcançado, pois foram coletadas as percepções dos participantes acerca do uso da Adaptação para colocar meia. Além disso, é uma contribuição deste estudo a adaptação dos questionários encontrados na literatura para uso em futuras pesquisas. O questionário de Çivitci (2004) foi traduzido e submetido a uma validação de equivalência semântica e idiomática entre suas versões original e traduzida. Foram feitas também sugestões de modificações nos questionários, com base na percepção dos participantes do estudo.

Um dos pontos a destacar é a recorrência de reclamações dos participantes quanto ao folheto de instruções do produto, o que demonstra que são necessárias melhorias significativas nesse aspecto para que o uso do produto seja satisfatório ou, inclusive, possível. Vale destacar que o dispositivo testado tem como um de seus pressupostos tornar o usuário mais independente em sua vida diária.

O estudo corroborou a necessidade de aplicação da ergonomia no processo de desenvolvimento de produtos, sempre considerando as limitações e habilidades dos usuários, procurando adaptar os produtos e serviços às pessoas. Nesse sentido, ressaltase a necessidade de envolver os usuários no desenvolvimento dos produtos de TA, conforme apresentado na revisão da literatura.

Outra sugestão é desenvolver estudos com uma amostra composta por mulheres idosas, as quais provavelmente apresentarão demandas, necessidades e 
problemas diferentes dos homens em sua relação com as roupas, bem como farão uma avaliação diferente em relação ao uso do dispositivo testado.

É necessário investigar o uso de outras TAs para vestir, ressaltando a relevância dessa AVD básica. Os autores tiveram dificuldade para encontrar o produto testado, tendo de comprá-lo em uma loja virtual. Da mesma maneira, retoma-se o fato de o Catálogo Nacional de Produtos de Tecnologia Assistiva apresentar apenas dois produtos de apoio para vestir e despir. A disseminação e o uso de dispositivos de TA para as AVDs pode melhorar a qualidade de vida dos idosos, bem como de outras pessoas com limitações funcionais.

\section{Artigo recebido em Setemnbro de 2016. Aprovado em Outrubro de 2016 DOI:http://dx.doi.org/105965/1982615×10192016150}

\section{Referências}

ABERGO. Definição internacional de ergonomia. Ação Ergonômica, [S.1.], v. 1, n. 2, 2001.

BRASIL. Decreto $n^{o}$ 5.296, de 2 de janeiro de 2004. Regulamenta as Leis $n^{o} 10.048$, de 8 de novembro de 2000, que dá prioridade de atendimento às pessoas que especifica, $e$ 10.098, de 19 de dezembro de 2000, que estabelece normas gerais e critérios básicos para a promoção da acessibilidade das pessoas portadoras de deficiência ou com mobilidade reduzida, e dá outras providências.

BRASIL. Lei $n^{o} 10.741$, de 1 de janeiro de 2003. Dispõe sobre o Estatuto do Idoso e dá outras providências.

BRUMMEL-SMITH, K.; DANGIOLO, M. Assistive Technologies in the home. Clinics in Geriatric Medicine, [S.1.], v. 25, n. 1, p.61-77, fev. 2009.

BÜHLER, C. Approach to the analysis of user requirements in assistive technology. International Journal of Industrial Ergonomics, [S.1.], v. 17, p.187-192, 1996. 
CARRIEL, I. R. R. Recomendações ergonômicas para o projeto de cadeira de rodas: considerando os aspectos fisiológicos e cognitivos dos idosos. 2007. Dissertação (Mestrado) - Universidade Estadual Paulista Julio de Mesquita Filho, Baurú.

ÇIVITCI, S. An ergonomic garment design for elderly Turkish men. Applied Ergonomics, [S.1.], v. 35, n. 3, p.243-251, maio 2004.

COSTA, E. C.; NAKATANI, A. Y. K.; BACHION, M. M. Capacidade de idosos da comunidade para desenvolver Atividades de Vida Diária e Atividades Instrumentais de Vida Diária. Acta Paul Enferm. São Paulo, p.43-48. 2006.

COOK, A. M.; POLGAR, J. M.; HUSSEY, S. M. Cook \& Hussey's assistive technologies: principles and practice. 3. ed. St Louis: Mosby Elsevier, 2008.

DUARTE, Y. A. O.; ANDRADE, C. L.; LEBRÃO, M. L. O Índex de Katz na avaliação da funcionalidade dos idosos. Rev Esc Enferm Usp. São Paulo, p.317-325. jun. 2007.

FARMER, S. E. et al. Assistive Technologies: can they contribute to rehabilitation of the upper limb after stroke?. Archives of Physical Medicine and Rehabilitation, [S.1.], v. 95, n. 5, p.968-985, jan. 2014.

GONÇALVES, E.; LOPES, L. D. Ergonomia no vestuário: conceito de conforto como valor agregado ao produto de moda. Modapalavra: reflexões em moda, Florianópolis, v. 4, p.22-29, nov. 2006.

IBGE. Projeção da população do Brasil e das Unidades da Federação, 2013.

IBGE. Projeções 1980-2050 - Revisão 2008, 2008.

IBGE. Tábuas abreviadas de mortalidade por sexo e idade: Brasil, Grandes Regiões e Unidades da Federação. Rio de Janeiro: IBGE, 2010. 
IIDA, I. Ergonomia: projeto e produção. 2. ed. São Paulo: Blucher, 2005

INTERNATIONAL ORGANIZATION FOR STANDARDIZATION. ISO 9999:2011: Assistive products for persons with disability - Classification and terminology.

MATSUDO, S. M.; MATSUDO, V. K. R.; BARROS NETO, T. L. Impacto do envelhecimento nas variáveis antropométricas, neuromotoras e metabólicas da aptidão física. Rev. Bras. Ciên. e Mov., v. 8, n. 4, p.21-32, 2000.

MELO, A. F. Avaliação de usabilidade em eletrodomésticos: o caso do forno de microondas. 2000. Dissertação (Mestrado) - Universidade Federal de Santa Catarina, Florianópolis, 2000.

MCT/SECIS. Catálogo Nacional de Produtos de Tecnologia Assistiva, 2015.

NIELSEN, Jakob; LANDAUER, Thomas K. A mathematical model of the finding of usability problems. Proceedings of ACM INTERCHI'93 Conference (Amsterdam, The Netherlands, 24-29 April 1993), pp. 206-213.

NIELSEN NORMAN GROUP. Why you only need to test with 5 users. 2000.

Disponível em: https://www.nngroup.com/articles/why-you-only-need-to-test-with-5users/. Acesso em: 25 out. 2016.

PAIVA, M. M. B.; SANTOS, V. M. V. Ergonomia no ambiente construído em moradia coletiva para idosos: estudo de caso em Portugal. Ação Ergonômica, [S.1.], v. 7, n. 3, p.56-75, 2012.

PASCHOARELLI, L. C. Conhecimento científico e a prática profissional da ergonomia: a contribuição da ergonomia física no design de produtos. In: BARBOSA, A. C. L. S.; RANGEL, M. M.; RAPOSO, M. (Org.). Ergonomia design usabilidade interação. Juiz de Fora: Mamm Ufjf, 2013. 
PLOS, O. et al. A universalist strategy for the design of Assistive Technology. International Journal of Industrial Ergonomics, [S.1.], v. 42, p.533-541, 2012.

ROBINSON, L. et al. Assistive technologies in caring for the oldest old: a review of current practice and future directions. Aging Health, [S.1.], v. 9, n. 4, p.365-375, ago. 2013.

SILVA, L. C. O design de equipamentos de tecnologia assistiva como auxílio no desempenho das atividades de vida diária de idosos e pessoas com deficiência, socialmente institucionalizados. 2011. Dissertação (Mestrado) - Universidade Federal do Rio Grande do Sul, Porto Alegre.

SILVEIRA, I. Aplicação da ergonomia no projeto do vestuário. Modapalavra: reflexões em moda, Florianópolis, v. 4, p.12-19, nov. 2006.

SPIRDUSO, W. W. Dimensões físicas do envelhecimento. Barueri, SP: Manole, 2005.

UNITED NATIONS, Department of Economic and Social Affairs, Population Division (2013). World Population Prospects: The 2012 Revision, Press Release (13 June 2013): "World Population to reach 9.6 billion by 2050 with most growth in developing regions, especially Africa".

VERAS, R.; DUTRA, S. Perfil do idoso brasileiro: questionário BOAS. Rio de Janeiro: UnATI UERJ, 2008.

WALDRON, D.; LAYTON, N. Hard and soft assistive technologies: defining roles for clinicians. Aust Occ Ther J, [S.1.], v. 55, n. 1, p.61-64, mar. 2008.

WESSELS, R. et al. Non-use of provided assistive technology devices, a literature overview. Technology and Disability, [S.1.], v. 15, p.231-238, 2003. 